\title{
The position and function of physical education in campus culture construction
}

\author{
Jian $\mathrm{Li}^{1, \mathrm{a}}$ \\ ${ }^{1}$ Shaanxi University Of Science \& Technology, Xi'an, Shaanxi Province, China \\ alijiantiyu@sust.edu.cn
}

Keywords:Sports, Physical education, Campus culture construction, Status and role

\begin{abstract}
In this article, through analysis on physical education and the function of campus culture both discussed the positive role of sports in the construction of campus culture. Think sports as a new form of campus culture, not only can promote the development of the whole campus culture, and it can effectively promote the campus spiritual civilization construction, is conducive to the completion of elementary education and the training target of high school students all-round development, at the same time, to enrich students amateur cultural life, improve students' cultural quality and aesthetic consciousness has a good effect. Therefore, to effectively play the role of sports in the construction of campus culture puts forward some Suggestions.
\end{abstract}

\section{Introduction}

With the rapid development of China's economy, China's economy has become an integral part of the world economy, construction industry as a pillar industry in China, in the economic construction of stimulating domestic demand, in a rare period of development. As China's market economic system gradually improve, in order to meet the demand of the market economy, to adapt to their corporate culture and brand benefit, must study of construction project management mode, and efforts to improve and innovate [1]. Although China state construction engineering construction enterprise has accumulated rich experience in project management have made great progress, but in the actual process of construction project management, many problems still exist, affect the survival and development of Chinese construction enterprise [1]. For China state construction engineering safety science construction. This paper mainly studies the Chinese construction engineering construction enterprise project management problems, to explore construction engineering management strategy, for the China state construction engineering construction enterprise to provide reference for the further development in the routine management.

\section{The characteristics and functions of sports}

The function of sports. Sports is a combination of fitness, healthy heart, strong and handsome, is a rich activity forms and exercise greater practical value of sports, exercise the following functions can be realized for a long time.

The function of physical fitness. A healthy person should have physical quality is good cardiopulmonary endurance, muscle strength, balance, agility, flexibility and coordination. Sports as a aerobic exercise, practice by a certain time and strength of the body, the body of each joint, ligament, the main muscle groups exert reasonable sports load and internal organs, which can effectively reduce weight, changes in body fat, such as body composition, improve cardiovascular, respiratory system and other internal organs function, development strength, endurance, speed, agility, flexibility and so on movement quality, enhanced physique, improve university students' physical growth and development, the healthy body, energetic [1].

The function of shaping figure. People take exercise its direct motive is the pursuit of physical beauty. Figure refers to the symmetry of human body shape, harmony, strong and handsome [2]. Congenital shape can be changed through physical exercise and the day after tomorrow. Sports in physiology, anatomy, sports aesthetics under the guidance of multi-disciplinary such as tight. Practice shows that it is one of the effective means of mold physique. University students are in the growth 
development period, is the best stage, to shape the form as a result, it is more popular sport in the campus.

Physical beauty is not a pure appearance of contour line is beautiful, but also for dynamic beauty. With sports training, whether standing or walking posture is stretch, generous and angry. Of course the most deep the most core is to have cultured and grace temperament of instrument. Therefore, inner beauty and lay a perfect combination of beauty is the pursuit of a high school student of the high level of physical beauty.

Cultivate the good thought quality. Sports not only need to have very good patience and self-control, psychological quality, but also have a strong will. Often take part in physical exercise is helpful to cultivate the good quality [2]. Sports by strengthening people's physique, improve the health of human body to raise people's confidence and change the mental outlook, increase a person's mental state, edify sentiment, purify the mind, give a person with aesthetic edification. Other collective sports, despite the relaxed and happy, but also to face the collective interests and personal interests, the contradiction of the need to constantly with the team spirit and collective spirit to overcome various difficulties and deal with interpersonal relations, in the long run, people's ideology and sacrifice realm will be effectively exercise.

\section{The status of sports in the construction of campus culture}

University campus culture is made up of sports culture and politics, ethics, science and technology, art, community culture, etc. Healthy campus culture needs both rigorous academic activities as the body of the supporting frame, and the style of lively and varied activities as flesh and blood. From the Angle of sociology, sports is a kind of social cultural phenomenon. People engaged in sports, the basic purpose is to the mind and body development and meet the requirements of their own senior, by sports to make their own body get distillation, the change of the spirit, so that people tend to perfection. As a sport loved by students, it has a variety of functions and activity form, rich variety of styles throughout the construction of campus culture can produce the following several aspects.

Promote the development of the whole campus culture. Sport was introduced to China from the $80 \mathrm{~s}$, has been widely university students' attention and welcome. Especially in recent years gradually in secondary schools in the country to promote and popularize rapidly, in a short period of time becomes the hot spot of university campus culture [3]. And sports activities carried out, and so did the campus sports heat to heat up, whether it is the square of the school, the playground, gym, or stages, sports fans can be seen everywhere - thus to promote the construction of campus culture. Also make the school sports activities display more vibrant scene, promote the development of the whole campus culture.

Promote the all-round development of human beings. Elementary education's aim is to cultivate the students to be moral, intellectual, physical all-round development of comprehensive talent. Physical education in elementary education occupy a large position, and is a part of the goal of the elementary education [3]. Sports as a sports teaching content, not only can enhance the student body and training students indomitable willpower, improve students' ideological and moral quality, increase the students' intelligence, can also entertainment, psychological adjustment and motivate students cohesion, build the optimization of educational environment, to achieve the training aim of the elementary education.

Cultivate the students' collective sense of honor. Sports is a group activities, to participate in various sports activities and games for a long time, and performance can deepen people's emotional communication and mental communication between each other, to cultivate students spirit of unity and cooperation, enhance the cohesion of the team, so as to cultivate the students' collective sense of honor, once the collective sense of honor, the students will naturally actively training in learning training will generate strong thirst for knowledge, can get along with each other and help each other, unity, friendship, and at the same time after the successful experiences will make them feel the personal effort and collective is inseparable, only work together, struggle together, to win honor for our collective, can gain a good result in some games and performances [4]. 
Cultivate the students to bear hardships and stand hard work, enterprising spirit. Sports will encounter many difficulties in the process of practice, such as the action is not coordination, flexibility, physical quality is poor, action cannot be put in place, etc., in practice a set of movements to five or six minutes, some even more than 30 minutes to exercise, exercise load larger needs certain endurance and strong willpower to accomplish [4]. Students need to have far, afraid tired spirit, perseverance stick to it, to achieve fitness results. After a long time of exercise, students will quality improved. Helpful to their learning and life.

Enrich the students' amateur cultural life. Sports has a strong mass, creative, artistic, entertaining, and in the campus sports culture activity content has an important position, has become a widely popular a kind of culture and art activities among university students. Sports rich content and spirit to change the fitness thousands of side hole of the traditional model for many years [5]. Because of its sort is more, different style, practitioners can lose no time, flexible to choose various styles of aerobics as content enrichment to exercise myself, such not only can exercise stimulate their enthusiasm, and will change the mental outlook of university students, active the atmosphere of group activities. In today's campus, sports games and performance has been widely carried out, the colleges and schools of all kinds of sports activities form, students can through these activities, performances, games to enrich his own amateur life, can also learn some knowledge about sports, and make the quality of their all-round development. At the same time can also increase the interaction between people, improve their social adaptation ability.

Improve the students' sports culture quality. Sports culture literacy refers to the various people combining moral elements and their quality and formed a kind of physical quality, it includes sports knowledge, sports knowledge, sports health knowledge, exercise and evaluation, competitive sports knowledge), sports skills (basic sports skills, physical exercise, entertainment, sports skill), sports consciousness, interest and habit [5]. By conducting sports interest group activities, lets the student can fully show their movement in the activities, to maintain the stability of the interest in exercise. Schools can through the rich campus sports culture activities, organize a variety of sports club in the form of teaching, make students achieve the goal of physical fitness, student teaching learning interest in the club, practice enthusiasm high, motor skills improve quickly. This and help to form lifelong exercise interest and ability and personality traits, so to the formation of students' sports culture accomplishment will have beneficial effects.

Improve the students' aesthetic consciousness. Sports is a pursuit of the human body health and beauty movement project, has the characteristics of sports and all kinds of arts high fusion, so it belongs to the category of art sports, with high artistic quality. Students in the process of practice can not only improve the ability of the body, fully show themselves, but also to feel beauty, appreciate beauty, exhibit beauty and create beauty, to gain the enjoyment of "beauty", improve the aesthetic consciousness and artistic accomplishment [5]. And sports athletes in the competition and performance of bodybuilding physique, superb technology, the smooth arrangement, the rhythm of the abundant physical strength and strong movement, etc., will give the students a beautiful impression, fully make students feel "health, strength, beauty" of the sport features and high artistic quality, and the influence of art, have been obtained to cultivate the noble aesthetic temperament and interest, to form correct aesthetic standards.

\section{The role of sports in the construction of campus culture}

To play the role of sports association. Sports fans on the one hand, through the sports lesson and extracurricular activities, learning the basic knowledge and skills, on the other hand, by joining sports association, and constantly improve their sports skill level [6]. Are different in many middle schools, from set up the name of the association of sports and community. Regular sports association may appoint professional teachers, regular hold sports training and guidance, let students with expertise and are interested in further training in their spare time, to enhance the fitness knowledge, improve the level of sports. Sports association at the same time can also regularly held different types, different difficulty, suitable for different levels of students to participate in the various forms of sports activities, attract students to attend the school, make the most of the students in exercise, participate in 
activities to improve the enthusiasm of the sport, so that the high school students after school life rich and colorful, to create a strong cultural atmosphere for the campus.

Strengthen the sports knowledge propaganda, to improve students' thinking and understanding [6]. Using the power of the media, enhance the promotion of sports fitness knowledge, make full use of campus radio, closed-circuit television, posters, blackboard, forms of propaganda, strengthen the sports culture atmosphere, one another, and let the students know more about sports characteristic, function and value, take the initiative to participate in sports.

Systematically carry out various kinds of sports activities. For active campus culture, improve the students' amateur cultural life, at the same time in order to promote communication among college students and improve technology, can through the campus culture management, school sports, sports association organization in a planned way, such as a variety of sports activities, such as competitions, performances, which not only make students have the opportunity to test their learned in sports in physical education, technology level, improve their ability, also can cultivate the students' competitive consciousness, trains the student to show self-confidence, cultivate students' teamwork spirit [3]. At the same time, it can stimulate the students' interest in sports, improve the enthusiasm of self-training, rather than simply watching.

\section{Summary}

Sports as a new exercise program, for its healthy body, the leisure entertainment, the psychological adjustment, performance competition, such as multi-functional overall effect, widely attention and loved by students in the school, also brought vitality to the campus culture and window. It promote the campus spiritual civilization construction, and promote the development of the whole campus culture, and improve the students' cultural quality and aesthetic consciousness, in the campus culture plays a fitness, education, advocacy, entertainment value, on campus cultural construction and development plays a role.

\section{References}

[1] Sh.B. Liu, Talking about the campus culture in physical education, Journal of Jilin institute of sport, 2002, vol.12, pp. 35-36.

[2] Zh.T. Li, Physical education and campus culture, Journal of Jilin institute of sport, 2003, vol.11, pp. 34-35.

[3] Y.S. Wang, The construction of college sports health function factor model and the practice research, Learn capital institute of physical education,2006, vol.11, pp.26-29.

[4] Y.D. Liu, Campus sports culture essence analysis, Journal of Xi'an sports institute, 2006, vol.7, pp. 116-117.

[5] N.Y. Zhang, The role of gymnastics in physical education teaching, Liaoning sports science and technology, 2003, vol.6, pp.71-76.

[6] F.L. Song, Culture construction of college education, Journal of Liaoning institute of technology, 2001, vol.3, pp.83-87. 